\title{
All for Him: Articles About Sex in American Lad Magazines
}

\author{
Laramie D. Taylor ${ }^{1}$
}

Research on sources of information about sex indicates that independent reading is a primary source of information for many young people. For young men, such reading is likely to involve lad magazines, a relatively new but very popular genre of lifestyle magazines targeted at young men. In the present study, a systematic representative sample of articles about sex from American lad magazines was subjected to content analysis. Results suggest that, although many articles focus on what women want sexually, the overall message of these articles privileges a fairly narrow male sexuality oriented toward sexual variety. At the same time, the normative relational context of sex is depicted as serious dating relationships. These results are consistent with predominant gender stereotypes about sex.

KEY WORDS: sex; magazines; content analysis.

In May of 2003, Wal-Mart elected to cease the sale of three popular magazines-Maxim, Stuff, and FHM: For Him Magazine. In justifying this decision, they cited customer complaints about the magazines' depictions of scantily clad women on their covers (Carr \& Hays, 2003). By banning these three titles, they effectively banned an entire genre of magazines, one that is relatively new to the United States-the lad magazine. Targeted at young men, these magazines are known for being "salacious but not pornographic" and for their "bawdy" humor (Carr, 2003). Given the popularity of the magazines in this new genre, as well as their overtly sexual content, it is possible, even likely, that they may play a role in teaching their young male readers about sex. In the present study, content analysis was used to explore what is being taught.

Current theories of sexuality emphasize that sexual behavior is, to a large extent, learned (Conrad \& Milburn, 2001; DeBlasio \& Benda, 1990; DeLameter, 1987; Levant, 1997). Although certain aspects of sexuality are physiological, the question of what is considered arousing, what behaviors and which partners are appropriate, when and in what contexts

\footnotetext{
${ }^{1}$ To whom correspondence should be addressed at Department of Communication Studies, 2020 Frieze Building, University of Michigan, Ann Arbor, Michigan 48109; e-mail: ldt@umich.edu.
}

sexual behaviors can be carried out, and what are the emotional, social, and psychological meanings of these various factors are must be learned.

The answers to the questions about sex posed above often differ based on one's gender. Numerous scholars have observed these differences, which seem to emphasize different roles and priorities for men and women in sexual encounters. Men are generally expected to be assertive seekers of sex and to value sexual frequency and variety; women, on the other hand, are expected to be sexual gatekeepers, recipients of men's attention, and to value sex only as part of committed romantic relationships, if then (DeLameter, 1987; Fine, 1988; Holland, Ramanzanoglu, Sharpe, \& Thomson, 2000; Levant, 1997; Phillips, 2000). Empirical evidence indicates that these expectations are often realized, as differences between men's and women's sexual behaviors, attitudes, and reactions to sexual stimuli, where observed, tend to be consistent with stereotypical expectations (Andersen, Cyranowski, \& Espindle, 1999; Aubrey, Harrison, Kramer, \& Yellin, 2003; Baumeister, Catanese, \& Vohs, 2001; DeLameter, 1987; Schmitt et al., 2003). Men in general seem to hold more permissive attitudes toward sex, to desire a greater variety of sexual partners and behaviors, and to seek sexual sensations more frequently than women do. 
In addition to information about gender roles, values, and so forth, there is a wide array of factual information pertaining to sex that can have important consequences; this includes topics such as possible unwanted consequences of sex, the prevention of such consequences, sexual disorders such as erectile dysfunction or vaginitis, the prevention and treatment of such disorders, and so on. That such information is vital is reflected in the facts that over one-third of adult women in the United States have a limited or incorrect understanding of how STDs can be contracted and that one in five adults in the United States have genital herpes (Kaiser Family Foundation, 2003).

Young people recognize their need to learn about sex. One national survey of a representative sample of young people ages 15-29 found that sexual health was the primary health topic of concern and interest among that population; $77 \%$ of the young people in the sample expressed an interest in receiving more information about sexual health (Kaiser Family Foundation, Hoff, Greene, \& Davis, 2003). Further, this and other studies have demonstrated that adolescents and young adults are able to name the sexual topics about which they need to be informed-they want to know more about specific sexual health topics, including symptoms, testing, and treatment of STDs, about how to use condoms correctly, about how sex and personal empowerment and happiness fit together, and about how to communicate with partners about sensitive sexual issues (Kaiser Family Foundation et al., 2003; Treise \& Gotthoffer, 2002).

\section{READING AS A SOURCE OF INFORMATION ABOUT SEX}

Adolescents and young adults receive information about sex from a number of sources; parents, peers, churches, media sources, and schools all make a contribution. When adolescents or young adults are asked to indicate their first or predominant source of information about sex, many cite peers or friends (Andre, Dietsch, \& Cheng, 1991; Andre, Frevert, \& Schuchmann, 1989; Ballard \& Morris, 1998; Kaiser Family Foundation et al., 2003). Other research, drawn from diverse samples and conducted over many years, suggests that for most topics related to sex, however, independent reading is a more important source of information than parents, peers, or schools (Andre et al., 1991; Andre et al., 1989; Bradner, Ku, \& Lindberg, 2000; Spanier, 1977). Further, these same studies suggest that this is true for both men and women, and for the sexually experienced as well as the less experienced.

\section{MAGAZINES AS SOURCES OF SEXUAL INFORMATION}

Though materials used for independent reading certainly vary, magazines are definitely one such source. Researchers who have employed diverse methods have arrived at the conclusion that adolescents and young adults use magazines to gain information about sexual topics including sexual skills and techniques, reproductive issues, sexual health, and alternative sexualities (Bielay \& Herold, 1995; Treise \& Gotthoffer, 2002), and that they often prefer magazines over other sources of information (Treise \& Gotthoffer, 2002). These findings, coupled with those that document independent reading as an important source of information about sex, suggest that magazines may be very important to the development of knowledge about, beliefs about, and attitudes toward sex, especially for young people.

There are theoretical reasons to believe that reading magazines to obtain sexual information may have effects on attitudes, beliefs, and behaviors, as well as information-type knowledge. Huesmann's (1997, 1998) information processing model suggests that numerous cognitive structures, including attitudes toward and beliefs about social objects, as well as scripts for behavior, can be incrementally learned, reinforced, or altered through essentially the same processes. Cultivation theory has long held that exposure to a consistent set of media messages can lead to altered beliefs about the nature of the real world (Gerbner, Gross, Morgan, Signorielli, \& Shanahan, 2002).

\section{EFFECTS OF USING INDEPENDENT READING AS A SOURCE OF INFORMATION ABOUT SEX}

There is little available research that deals with the issue of what effects, if any, independent reading about sex in general, or reading about sex in magazines in particular, has on readers. What is available is largely correlational in nature. There is an 
association between receiving more sexual education from independent reading and better performance on a test of knowledge about sex (Andre et al., 1991). There is also some evidence that receiving more information from independent reading as opposed to other sources may be associated with more sexual experience (Andre et al., 1991); given the numerous plausible explanations for such observations, however, it is premature to infer a causal relationship. In addition, in one study, reading sex manuals and reading Playboy were each associated with beliefs about greater frequency of behaviors including sexual intercourse, oral sex, and erotic dreams, and reading Playboy was associated with beliefs that sex without love, the use of stimulants for sex, and the exchange of sex for favors were relatively more common (Buerkel-Rothfuss \& Strouse, 1993). Another study found reading women's lifestyle magazines such as Cosmopolitan and Elle to be associated with greater endorsement of sexual stereotypes (Kim \& Ward, 2004). Limited experimental evidence also indicates that viewing nonpornographic sexual images from magazines can lead to greater endorsement of rape-supportive attitudes (Lanis \& Covell, 1995; MacKay \& Covell, 1997).

\section{SEXUAL MESSAGES IN POPULAR MAGAZINES}

Given the apparent influence of magazine content and the importance of independent reading in general, and magazines in particular, as sources of sexual information for young people, it is important to understand what messages about sex are contained in the magazines read by young people. Relatively little research is available on this topic, and what is available is largely concerned with magazines targeted at young women. A broad range of sexual topics are apparently available in women's magazines such as Cosmopolitan, including topics as diverse as contraception, sexual technique, and sex addiction, though sexual techniques and pleasuring seem to be most common (Bielay \& Herold, 1995); topics of magazines targeted at younger women generally focus on establishing and maintaining romantic relationships and sexual decision-making, though sexual health issues and techniques are also present (Carpenter, 1998; Garner, Sterk, \& Adams, 1998). Magazines targeted at adolescent girls, such as Seventeen and $Y M$, have been found to contain conflicting messages about sex; they encourage girls to be sexy, emphasize the importance of romantic relationships, instruct young women on how to please young men, and simultaneously emphasize patience and control (Carpenter, 1998; Durham, 1998; Garner et al., 1998). Studies of magazines targeted at adult audiences, both male and female, such as Cosmopolitan, Self, GQ, and Playboy, have demonstrated that their contents treat women as sex objects, both through use of objectifying images (Krassas, Blauwkamp, \& Wesselink, 2001) and the written content of articles about relationships (Duran \& Prusank, 1997).

Despite the relatively important role they may play in the development of young people's attitudes toward and beliefs about sex, there is a surprising paucity of research on the nature of sexual content in magazines targeted at young people, especially young men. What little research is available on men's magazines has focused on magazines such as Playboy, Penthouse, and GQ; these magazines are designed for and marketed to adult men in general, and not to adolescent boys and young adult men in particular. Further, magazines such as Playboy, despite their ostensible status as "lifestyle magazines," seem to be in a very different category than lifestyle magazines such as Cosmopolitan that are oriented toward women.

\section{SEX IN LAD MAGAZINES}

There is, however, a genre of magazines that is targeted principally at young men and that does parallel, in many ways, women's lifestyle magazines: so-called "lad" magazines such as Maxim, Stuff, and $F H M$. These magazines, modeled after successful British magazines, are targeted at young men and, although they do feature enough scantily clad models to be banned from some retail stores (Carr \& Hays, 2003), they do not contain even frontal nudity. These magazines debuted in the late 1990s in the United States, and they have rapidly established a firm cultural presence. Maxim, the oldest and most successful of the genre, has a readership of over 12 million; according to Maxim's own data, their readership is overwhelmingly male $(76 \%)$, unmarried $(71 \%)$, and fairly young (the median age of readers is 26) (Maxim Online, 2003). Other magazines of this genre have smaller followings, but with similar, or even younger, demographic characteristics.

The study described here was undertaken to explore the nature of the messages about sex contained 
in these magazines. There were several goals in this exploration. First, an attempt was made to discover what specific topics were addressed in articles that were predominantly about sexual subjects. As discussed above, past research suggests that young people want information about sexual health and personal empowerment issues; they want to read about specific STDs, their prevention and treatment, and about how to negotiate condom use with a partner (Kaiser Family Foundation et al., 2003; Treise \& Gotthoffer, 2002). At the same time, we know that women's magazines focus more on sexual techniques and pleasuring than on such information, though they do give substantial attention to issues related to women's reproductive health (Bielay \& Herold, 1995). Given traditional gender roles that portray women as sexual gatekeepers and men as sexually driven (DeLameter, 1987; Phillips, 2000), we would expect an even greater emphasis on topics related to sexual gratification than those related to sexual health in lad magazines than has been observed in women's magazines. Further, we should observe a clear focus on men's sexuality and sexual outcomes as opposed to women's sexual outcomes.

The second objective of this project was to determine what sexual topics were, though not the primary subject of a given article, embedded in articles about sex. It may be that certain subjects that are underrepresented as foci of entire articles are nonetheless amply represented as elements of other articles. Such is seemingly the case with the presence of messages about condom use on television; although few scenes deal with condom use as a primary subject, relatively more scenes about specific sexual encounters incorporate condom use (Kunkel et al., 2003). To understand the nature of the sexual content in these articles, it is necessary to understand all of the topics, rather than just the predominant subject, that are discussed within them.

The third goal was to assess the nature of the relationships presented as the contexts for sexual activity within these magazines. Given repeated findings that men tend to privilege variety among sexual partners (Baumeister et al., 2001; DeLameter, 1987; Schmitt et al., 2003), it was expected that most articles about sex in magazines targeted at young men would presume fairly low-commitment relationships as the context for sexual activity, such as strangers or casual dating relationships. Alternately, it may be that relatively more committed relationship states are presented as contexts for sexual activity, but that such relationships are portrayed negatively.

\section{METHOD}

\section{Sample}

Three magazines were identified for inclusion in this study due to their predominance within the genre-Maxim, Stuff, and FHM (For Him Magazine). These magazines are often linked together in the popular press, as well as by Wal-Mart executives, who banned the sale of all three in 2003 (Carr, 2002; Carr \& Hays, 2003). They are also the oldest of their genre in the United States (Carr, 2002), and each ranks among the 100 most widely read magazines in the United States (Information Please, 2003).

A systematic random sample of magazines was drawn by selecting 4 months of the year at random (March, May, August, and October) and obtaining an issue of each magazine for each of those 4 months for every year of each magazine's publication through the issue published in May of 2003. This yielded differing sample sizes for each of the three titles because the magazines were founded at different times-Maxim began publishing in the United States in mid-1997, FHM in early 2003, and Stuff in mid1999. Three specific issues in the sample could not be located; in these cases, the ensuing month's issue of the same magazine was substituted. Initial examination of issues of each title from different years suggests that differences between the magazines' sexual content are minimal.

All articles primarily about a sexual topic in the magazines were included in the sample. The determination of which articles would be included was made primarily by examining the table of contents. An article was defined as a body of editorial content described under a single heading in the table of contents. Articles determined to be about a sexual topic included those for which the primary topic discussed in the article's prose content dealt with sexual behaviors or relationships, their antecedents, or their consequences. Articles that consisted primarily of pictorials of women described in terms of sex appeal were not included. A total of 91 articles from 53 different issues met these criteria, and they constituted the sample of articles about sex.

\section{Coding Scheme and Definitions}

Articles were coded first for their primary topic and then for any other topics that received substantial attention in the article. The list of topics included 
in the coding scheme was adapted from Bielay and Herold's (1995) study of sexual topics in women's magazines by adding topics specific to men's sexual health and pleasure. Coders were provided with a list of topics and asked, after reading the entire article, to select which one, if any, was the primary emphasis of the article. Topics included in this list were improving one's sex life, what women like, improving one's orgasm, improving a woman's orgasm, sexual satisfaction, unorthodox sexual behaviors or positions, unorthodox sexual locations, HIV/AIDS, other STDs, rape, safe sex, pregnancy, condoms, women's sexual health, abortion, vasectomy, other men's sexual health issues, gay men, lesbians, and drugs or alcohol. Although definitions for many of these are self-evident (e.g., HIV/AIDS, pregnancy), others required further development and clarification. A single article could only have one primary topic, but could mention numerous topics. These were coded for separately, but using the same basic definitions (see below).

\section{Improving One's Sex Life}

Content that discusses betterment of one's sex life in general, such as suggesting strategies for getting more sex, better sex, or sex more consistent with the reader's desires and interests.

\section{What Women Like}

Describes women's preferences, likes, and dislikes relative to sex or sexual relationships. Possible content could include descriptions of sexual techniques women endorse or personality or physical traits women find appealing in potential sex partners.

\section{Sexual Satisfaction}

Discusses the nature of sexual satisfaction, or being contented or pleased with one's sexual experiences or sex life, or offers a definition of what constitutes sexual satisfaction. This is distinct from improving sex life in that sexual satisfaction does not presume current dissatisfaction or necessarily recommend change. An article that suggests that the key to sexual satisfaction is to moderate one's expectations, for example, would really not focus on improving one's sex life, but on being satisfied with the sex life one has.

\section{Unorthodox Sexual Behaviors or Positions}

Descriptions of sexual behaviors other than precoital behaviors such as kissing and petting, genital intercourse, and oral-genital intercourse, or specific methods of the same that were deemed unusual or extreme. Examples used in coder training included group sex, anal sex, and bondage not described as "playful"or "light." This category also included descriptions of sexual positions that seemed complicated, contorted, or acrobatic in nature.

\section{Unorthodox Sexual Locations}

Descriptions of sexual encounters in places other than a place of residence such as a home, apartment, or hotel, or those that, although in a place of residence, occurred in unexpected locations or atop unusual items of furniture. Sex in bed, on a chair or couch, or on the floor was not considered to occur in an unusual location.

\section{Drugs and Alcohol}

This category strictly referred to content in which drugs or alcohol was connected in some way to sexual behaviors, gratifications, or outcomes. Articles about beer would not fit this category; articles that discussed bars where alcohol is served as places to recruit sexual partners, however, would.

\section{Relationship States}

Each article was also coded for the predominant relationship state, if any, presumed to be the context of sexual activity as discussed within the article. Seven relationship states were coded: strangers, first date, casually dating, seriously dating, engaged, married, and nonromantic acquaintance (definitions can be found in Table I).

In addition, coders were asked to determine the degree to which each article depicted the main relationship state to be positive and negative, either through overt statements or implication. In order to account for possible ambivalence toward a relationship state, positivity and negativity toward relationship state were coded separately. Each article in which a dominant relationship state was observed was therefore coded for relationship positivity, the 
Table I. Definitions of Relationship States

\begin{tabular}{ll}
\hline Strangers & Individuals who are not romantically involved, have not dated \\
First date & On or immediately after a first date that is stated to be such \\
Casually dating & Nonexclusive dating, dating that is relatively low on commitment \\
Seriously dating & $\begin{array}{r}\text { Relatively exclusive dating, moderate to high level of commitment; } \\
\text { signaled by terms like "girlfriend," indications of possession, etc. } \\
\text { Engaged, formally intending to marry } \\
\text { Engaged }\end{array}$ \\
$\begin{array}{l}\text { Married } \\
\text { Nonromantic acquantance }\end{array}$ & $\begin{array}{l}\text { Not dating nor romantically involved, but also not strangers. Would } \\
\text { include ex-girlfriends, friends, well-known co-workers }\end{array}$ \\
\hline
\end{tabular}

degree to which a relationship state is implied or stated to be positive, beneficial, or a source of positive outcomes, and relationship negativity, the degree that a relationship is implied or stated to be negative, harmful, limiting, or a source of negative outcomes. Although this was done initially on a fivepoint scale (where 0 indicated no positivity or negativity, 1 indicated mild, 2 some, 3 moderate, and 4 indicated extremely positive or negative), low intercoder reliability required the collapse of intermediate scores of 2 and 3 into a single score, which resulted in a 4-point scale.

\section{Images}

Each article was also coded as to the nature of the photographic images that accompanied it; following the pattern established by Reichert, Lambiase, Morgan, Carstarphen, and Zavoina (1999), cartoons and illustrations were excluded. The presence of members of each sex in such images was coded, as were the explicitness of those images and the nature of the interpersonal contact, if any, that they depicted. In order to maintain a consistent unit of analysis, individual photographs were not analyzed; instead, coders identified whether any photograph that accompanied an article contained each element in the coding scheme. An article with three photographs of women was coded the same as an article with a single photograph of a woman. In the case of explicitness, the photograph with the highest degree of explicitness was used.

Explicitness was measured on a scale based largely on those employed by Kunkel et al. (2003) for their analysis of sexual content on television and Reichert et al. (1999) for their analysis of images in magazine advertisements. Five categories were employed; images were coded as not explicit (0), suggestive (1), begin disrobing (2), discreet nudity (3), and nudity (4). Photographs were coded as suggestive if a model's attire was considered to reflect a strong effort to display one's body in a sexual manner and included bikinis, very short skirts, and sheer tops. Photographs in the "begin disrobing" category depicted an individual apparently in the process of removing clothing, which, if removed, would reveal often sexualized body parts, specifically buttocks, genitals, or a woman's breasts; models who were wearing only very revealing undergarments were included in this category. Discreet nudity indicated portrayals in which nudity was strongly suggested without showing genitals or women's nipples, though the rest of the breast could be visible. Finally, photographs were coded as depicting nudity if genitals, entire buttocks, or a woman's nipple or nipples were visible and unobscured.

Interpersonal contact was measured using a rubric developed by Reichert et al. (1999); images were coded as not having an eligible couple (0), containing at least two people engaging in no physical contact (1); simple contact (2) such as a casual embrace; intimate contact (3) such as kissing, embracing suggestively, or caressing; or very intimate contact (4) such as sexual intercourse or other direct sexual stimulation. The gender of each pair was also coded.

\section{Coder Training and Reliability}

Two paid coders, both male students enrolled at a large midwestern university, conducted all coding activities for this project. They received 8 hours of training in which they learned the definitions, were presented with examples of content that represented each type, and practiced coding articles from issues of lad magazines not included in the sample. Through repeated practice and discussion about coding decisions, coders demonstrated an understanding of relevant constructs and decisions.

Intercoder reliability was assessed using Cohen's kappa as described by Neuendorf (2002), calculated 
for each topic, relationship state, and explicitness rating. A total of 20 articles from the sample, chosen at random, were coded by both coders. All kappas were above .70, which, given the exploratory nature of this study, the conservative nature of Cohen's kappa as a tool for assessing intercoder reliability, and the relatively small sample size (due, in part, to the relative newness of the genre being studied), was considered to be a good indicator of reliability (for a detailed discussion of acceptable levels of intercoder reliability, see Neuendorf, 2002). The two exceptions to this were relationship positivity and negativity, which, as discussed above, did not reach acceptable levels of reliability (.51 and .39 , respectively); for each, the categories of "some" and "moderate" were collapsed into a single category, improving the kappas to acceptable levels (above .70).

\section{RESULTS}

\section{Main Topics of Articles About Sex}

Only a handful of the topics coded were represented as main topics of articles in the sample. The most common topic was what women like (37 articles or $41 \%$ ); this was followed by unorthodox sexual behaviors or positions (18 articles or $20 \%$ ) and improving sex life (17 articles or 19\%). Articles focused on unorthodox locations for sex (6 articles or 7\%), improving women's orgasms ( 3 articles or $3 \%$ ), men's sexual health issues, and sexual satisfaction (1 article or $1 \%$ each) were also identified. Eight articles did not have an identifiable main topic that fit the coding scheme.

Perhaps as relevant as what is present is what is missing; there were no articles focused on alternative sexualities (gay men, lesbians) whatsoever. There was also an absence of any articles focused on risks associated with pregnancy (pregnancy, abortion, STDs, HIV/AIDS) or the prevention of those risks (safe sex, vasectomy, condoms). The sole article focused on sexual health consisted entirely of trivia that pertained to sexual functioning and health, such as the effect of zinc on sperm motility and reasons used to justify circumcision.

\section{Secondary Topics}

In addition to coding for a single, dominant topic for each article, coders also indicated all topics that received substantial mention within each article. A substantial mention was one that was considered to be clear and relatively unambiguous. For example, in an article whose main topic is what women like, an explicit statement about group sex would be coded as a substantial mention of unorthodox sexual behaviors; a veiled reference to the same behavior such as a reference to "heading down the hall together" would not be coded.

The most common secondary topic was improving sex life, present in 47 of 91 articles (52\%). This was followed closely by unorthodox sexual behaviors (39 articles or $43 \%$ ), unorthodox sexual locations (35 articles or $38 \%$ ), drugs or alcohol (34 articles or $37 \%$ ), and what women like (33 articles or $36 \%$ ) (for all frequencies, see Table II). Of these, only drugs and alcohol were not among the most frequent main topics as well. Clearly, a few topics overwhelmingly dominate articles about sex in American lad magazines. If young men are using these magazines as sources of sex education, they are learning about a very limited range of topics.

\section{Intersections Between Topics}

Several intersections exist between the more common main and secondary topics that may shed additional light onto the content of articles about sex in these magazines. For example, articles that are principally focused on what women like are also very likely to contain messages about improving men's sex life (25 of 37); in fact, chi-square analysis suggests that they were significantly more likely to contain such messages than expected by chance, even given the overall frequency of such messages in articles on all topics, $\chi^{2}=18.64, p<.001$. Articles principally focused on what women want were also more likely to contain mention of unorthodox sexual practices than would be expected by chance, $\chi^{2}=16.62, p=$ .002 , but no more likely to mention unorthodox sexual locations, $\chi^{2}=4.50$, n.s.

There were insufficient mentions of sexual health topics to conduct any sort of statistical analysis, but it is interesting to note where these mentions did occur. Three of the five mentions of safe sex occurred in articles focused on unorthodox sexual behaviors; the other two were in articles with no identifiable main topic. There were no mentions of safe sex in articles primarily about what women want, and only two such articles mentioned condoms. On the other hand, nearly one-half of all articles that 
Table II. Frequencies of Articles Principally About and Containing Mention of Sexual Topics

\begin{tabular}{lccc}
\hline \multicolumn{1}{c}{ Topic } & $\begin{array}{c}\text { Number of articles } \\
\text { with topic as } \\
\text { primary focus }\end{array}$ & $\begin{array}{c}\text { Number of articles } \\
\text { with substantial } \\
\text { mention of topic }\end{array}$ & $\begin{array}{c}\text { Total number } \\
\text { of articles } \\
\text { mentioning topic }\end{array}$ \\
\hline Improving sex life & 17 & 47 & 64 \\
What women like & 37 & 33 & 70 \\
Improving orgasm & 0 & 3 & 3 \\
Improving a woman's orgasm & 3 & 8 & 11 \\
Sexual satisfaction & 1 & 15 & 16 \\
Unorthodox sexual behaviors or positions & 18 & 39 & 57 \\
Unorthodox sexual locations & 6 & 35 & 41 \\
HIV/AIDS & 0 & 2 & 2 \\
STDs & 0 & 5 & 5 \\
Rape & 0 & 0 & 0 \\
Safe sex & 0 & 5 & 5 \\
Pregnancy & 0 & 4 & 4 \\
Condoms & 0 & 11 & 11 \\
Women's sexual health & 0 & 6 & 6 \\
Abortion & 0 & 0 & 0 \\
Vasectomy & 0 & 0 & 0 \\
Other men's sexual health issues & 1 & 7 & 8 \\
Gay men & 0 & 3 & 3 \\
Lesbians & 0 & 17 & 17 \\
Drugs or alcohol & 0 & 34 & 34 \\
\hline
\end{tabular}

mentioned condoms were primarily about unorthodox sexual behaviors or locations; specific examples of such articles concern the convenience of having sex in public places where condom machines are located and deride the masculinity of a man who opens a box of condoms in front of a new sexual partner. Articles that included mentions of other men's sexual health topics were predominantly focused on improving readers' sex lives or on unorthodox sexual practices, and they often took the form of unusual trivia, such as the percentage of sperm that are fertile in the average man.

\section{Relationship States}

Of 91 articles about sex, 73 were coded as stating or clearly implying a single dominant relationship state presumed to be the context for sexual activity. The most common relationship state was serious dating (44 articles). These articles often made explicit references to committed relationship roles by referring to "your girlfriend" or "your girl." Others implied such a relationship with a combination of mentions of longer relationships and expectations of sexual exclusivity. The next most common relationship state was strangers (17 articles). The first date (3 articles), a casual dating relationship (3 articles), and nonromantic acquaintances (4 articles) also re- ceived some attention. Only one article presumed engagement or marriage as a context for sex.

Most articles that depicted serious dating as the context for sexual activity portrayed it ambivalently. Only 15 articles in this group were coded as strictly positive or negative toward the serious dating relationship; the rest conveyed a combination of both. Most of the articles (27 of 44 or $61 \%$ ) were moderately positive about serious dating relationships; of these, 10 were also moderately negative, and 8 were mildly negative. Only two articles were rated as highly positive toward serious dating relationships, and only two were rated as highly negative. Relationship positivity overall was mild to moderate $(M=1.52, S D=.73)$; relationship negativity was just slightly lower $(M=1.27, S D=.84)$.

Similar patterns emerged for articles that depicted strangers as the relationship context for sex. None of these articles portrayed this context as extremely positive or negative, and most articles were ambivalent (11 of 17 , or $65 \%$ ). Scores for positivity seem to be slightly higher than scores for negativity $(M=1.53, S D=.80$ and $M=1.00, S D=.70$, respectively).

The one article that featured married sex was also ambivalent. The article discussed the practice of married couples inviting another individual to join them in group sex as both an enlightened practice for the most sincerely committed and as an attempt 
to breathe life into the impractical, unrealistic sexual world that is marriage.

\section{Images}

All articles in the sample were accompanied by at least one photograph, and so all were included in the following analysis. Of the 91 articles in the sample, 89 were accompanied by a picture of a woman; the median explicitness was 2 , or "begin disrobing." This was also the modal category (43 articles), followed by discreet nudity ( 21 articles), and suggestive appearance (17 articles). Only one article was accompanied by an image that met the description of nudity. Nearly one-half of the articles in the sample (45) included a picture of a man, although the median explicitness was much lower than that for women $(M d=.40)$. Most images (25) were not explicit; nine articles included an image of a man suggestively attired, 10 were partially disrobed, and one exhibited discreet male nudity.

Thirty-seven articles included photographs of men and women together; of these, 17 included a depiction of intimate contact, and five included a depiction of very intimate contact. Simple contact occurred in nine articles, and no contact in six.

Articles accompanied by images of multiple women were also fairly common (33 articles). Most of these depicted no contact (9) or simple contact (14) between or among the women in the photograph; a few (9) depicted intimate contact, and one depicted very intimate contact between two women. Only nine articles in the sample included more than one man; of these, seven depicted no contact between the men, and the other two depicted simple contact.

\section{DISCUSSION}

The most common topics of articles about sex in American lad magazines are what women want, how to improve one's sex life, and unorthodox sexual positions and locations. The last three of this group were expected and consistent with cultural norms that describe sex in generally androcentric terms and male sexuality as oriented toward maximizing variety. The fact that the most common topic, what women want, seems, at first glance, to be inconsistent with this pattern will be taken up later.

The finding that improving the male reader's sex life was a prominent topic is hardly surprising, yet is nonetheless important. After all, if lad magazines are being used as sources of sex education, what are readers learning? First, as they read repeatedly about how to improve their sex life, they are likely to learn that their sex life is presently inadequate. Otherwise, it would not need improving. Second, readers may learn that they can improve it along fairly narrowly defined lines-lines suggested, for example, by the next most common topics, specifically unorthodox sexual locations and positions, and by other topics frequently mentioned in these articles, such as use of alcohol. Ultimately, these articles seem very clearly to emphasize an androcentric sexuality that emphasizes sexual variety.

To understand the exception to this pattern, specifically the phenomenon that the most common topic of articles about sex in the sample was what women want, we must look beyond the primary topic of those articles and explore their contents further. After all, most of those articles also contained discussion of improving the presumably male readers' sex life. It is possible that such mentions alter the fundamental meaning of the articles in which they occur. Examination of examples of such articles makes this clear. One article in Maxim titled "More Sex Now!" suggested a number of strategies for pleasing a woman and helping her to enjoy sex more. These included talking dirty, giving her surprise gifts, and extending foreplay. The initial paragraphs of the article, however, as well as the title, signal that the male reader should engage in such behaviors in order to increase the frequency and enthusiasm of sexual intercourse. This is echoed throughout the article, as the author promised that the specific behaviors presented as what women desire will result in sexual rewards for men, as when she stated that "we'll go out of our way to express our gratitude (read: blow job), and presto: Your sex life's back." Another article features a discussion among six women about what makes a potential male partner appealing and a present sex partner worth keeping; the article, written entirely from a woman's perspective, emphasized women's wants, yet the opening paragraph encouraged the male reader to use the article as a "guided tour through a first encounter and beyond" in order to "make sure" they get what they want sexually.

Thus, articles about what women want are essentially framed in terms of improving men's sexual experiences. The message is that if you give women what they want, then your sex life will improve. Essentially, then, any such article is consistent with the expectation that articles about sex in lad magazines 
will reinforce traditional masculine gender norms about sex, as women's sexual experience serves as a pathway to the fulfillment of men's sexual goals.

This is further reinforced by the frequent occurrence of mentions of unorthodox sexual behaviors in articles about what women want. The message of such articles is that women want to engage in unusual sexual behaviors as much as men do, that women are driven by sexual variety just as men are. This is exemplified by articles in which women are quoted as they enthuse over bondage, sex in public, group sex, and the use and imitation of pornography during sex. The implicit message is that women's and men's sexual desires are essentially similar (for discussions of the similarities and differences between men's and women's sexuality, see Baumeister et al., 2001; Oliver \& Hyde, 1993; Schmitt et al., 2003).

The finding that 17 articles mentioned lesbianism also, at first glance, seems inconsistent with expectations about androcentric messages about sex. Closer examination, however, indicates that most such references are actually about women engaging in sex with other women while men watch or participate. A few others consist of descriptions of sexual encounters with women by women who claim to be bisexual which, at least in their description in print, could be seen as essentially serving to further men's sexual satisfaction. In short, these references are also essentially oriented toward men's sexual outcomes.

The fact that most of the articles about sex in these magazines are accompanied by images of women depicted suggestively or only partially clothed may reinforce this notion. Regardless of the subject matter of an article, it is accompanied by a sexualized image of at least one woman. This may serve to influence the meaning readers ascribe to any content. The images themselves may function to activate stereotypes about women as sex objects; these stereotypes would then be expected to influence how readers understand what they read. Articles about what women want sexually, for example, may be understood even more in terms of men's pleasure than would otherwise be the case.

Another unexpected outcome is more difficult to explain. Although it was expected that information about the positivity and negativity of various relationship states depicted as the contexts for sex would ultimately privilege relatively uncommitted relationships, it was found that both committed (steady or serious dating) and uncommitted (strangers) relationships were portrayed ambivalently. This may have important consequences for readers, though those consequences are unlikely to be simple. Readers may learn that no relationship state is a perfect context for sex and that there are benefits drawbacks both to having sex with strangers and to having sex with a committed romantic partner. They may also learn what those respective drawbacks and benefits are, which may shape their own sexual decisions.

Ultimately, it seems that these magazines offer little in the way of sexual information that is different from the broad, stereotypical perceptions of sex as androcentric and men's sexuality as focused on variety. Even articles that seem to contradict such notions ultimately seem to reinforce them. Of course, whether or not this reinforcement occurs, and whether magazine articles such as those included in the present study reinforce or change the attitudes of readers are ultimately questions for experimental studies.

\section{ACKNOWLEDGMENTS}

The author wishes to thank Trek Glowacki for his work as primary coder on this project and Monique Ward for guidance in its early stages.

\section{REFERENCES}

Andersen, B. L., Cyranowski, J. M., \& Espindle, D. (1999). Men's sexual self-schema. Journal of Personality and Social Psychology, 76, 645-661.

Andre, T., Dietsch, C., \& Cheng, Y. (1991). Sources of sex education as a function of sex, coital activity, and type of information. Contemporary Educational Psychology, 16, 215-240.

Andre, T., Frevert, R. L., \& Schuchmann, D. (1989). From whom have college students learned what about sex? Youth and Society, 20, 241-268.

Aubrey, J. S., Harrison, K., Kramer, L., \& Yellin, J. (2003). Variety versus timing: Gender differences in college students' sexual expectations as predicted by exposure to sexually oriented television. Communication Research, 30, 432-460.

Ballard, S. M., \& Morris, M. L. (1998). Sources of sexuality information for university students. Journal of Sex Education and Therapy, 23, 278-287.

Baumeister, R. F., Catanese, K. R., \& Vohs, K. D. (2001). Is there a gender difference in strength of sex drive? Theoretical views, conceptual distinctions, and a review of relevant evidence. Personality and Social Psychology Review, 5, 242-273.

Bielay, G., \& Herold, E. S. (1995). Popular magazines as a source of sexual information for university women. Canadian Journal of Human Sexuality, 4, 247-261.

Bradner, C. H., Ku, L., \& Lindberg, L. D. (2000). Older, but not wiser: How men get information about AIDS and sexually transmitted diseases after high school. Perspectives on Sexual and Reproductive Health, 32, 33-38.

Buerkel-Rothfuss, N., \& Strouse, J. S. (1993). Media exposure and perceptions of sexual behaviors: The cultivation hypothesis 
moves to the bedroom. In B. S. Greenberg, J. D. Brown, \& N. Buerkel-Rothfuss (Eds.), Media, sex, and the adolescent (pp. 225-246). Cresskill, NJ: Harper.

Carpenter, L. M. (1998). From girls into women: Scripts for sexuality and romance in Seventeen magazine, 1974-1994. Journal of Sex Research, 35, 158-168.

Carr, D. (2002, July 29). British publishers attack U.S. and take young male readers. New York Times, p. C1.

Carr, D. (2003, October 20). Maxim's 'hidden' cover spoofs breathless headlines. New York Times, p. C1.

Carr, D., \& Hays, C. L. (2003, May 6). 3 racy men's magazines are banned by Wal-Mart. New York Times, p. C1.

Conrad, S., \& Milburn, M. (2001). Sexual intelligence. New York: Crown.

DeBlasio, F. A., \& Benda, B. B. (1990). Adolescent sexual behavior: Multivariate analysis of a social learning model. Journal of Adolescent Research, 5, 449-496.

DeLameter, J. (1987). Gender differences in sexual scenarios. In K. Kelley (Ed.), Females, males, and sexuality: Theories and research (pp. 127-139). Albany, NY: State University of New York Press.

Duran, R. L., \& Prusank, D. T. (1997). Relational themes in men's and women's popular nonfiction magazine articles. Journal of Social and Personal Relationships, 14, 165-189.

Durham, M. G. (1998). Dilemmas of desire: Representations of adolescent sexuality in two teen magazines. Youth and Society, 29, 369-389.

Fine, M. (1988). Sexuality, schooling, and adolescent females: The missing discourse of desire. Harvard Educational Review, 58, $29-52$.

Garner, A, Sterk, H. M., \& Adams, S. (1998). Narrative analysis of sexual etiquette in teenage magazines. Journal of Communication, 48, 59-78.

Gerbner, G., Gross, L., Morgan, M., Signorielli, N., \& Shanahan, J. (2002). Growing up with television: Cultivation processes. In J. Bryant \& D. Zillmann (Eds.), Media effects: Advances in theory and research (pp. 43-68). Mahwah, NJ: Erlbaum.

Holland, J., Ramanzanoglu, C., Sharpe, S., \& Thomson, R. (2000). Deconstructing virginity: Young people's accounts of first sex. Sexual and Relationship Therapy, 15, 221-232.

Huesmann, L. R. (1997). Observational learning of violent behavior. In A. Raine, P. A. Brennen, D. P. Farrington, \& S. A. Mednick (Eds.), Biosocial bases of violence (pp. 69-88). New York: Plenum.

Huesmann, L. R. (1998). The role of social information processing and cognitive schema in the acquisition and maintenance of habitual aggressive behavior. In R. G. Geen \& E. Donnerstein (Eds.), Human aggression: Theories, research, and implications for social policy (pp. 73-109). New York: Academic Press.

Information Please (2003, October 13). Top 100 consumer magazines 2002. Retrieved from http://www.infoplease.com/ipea/ A0301522.html
Kaiser Family Foundation (2003, June). Fact sheet: Sexually transmitted diseases in the U.S. Retrieved from http://www.kff.org/ content $/ 2003 / 3345 /$.

Kaiser Family Foundation, Hoff, T., Green, L., \& Davis, J. (2003). National survey of adolescents and young adults: Sexual health knowledge, attitudes, and experiences. Menlo Park, CA: Henry J. Kaiser Family Foundation.

Kim, J. L., \& Ward, L. M. (2004). Pleasure reading: Associations between young women's sexual attitudes and their reading of contemporary women's magazines. Psychology of Women Quarterly, 28, 48-58.

Krassas, N. R., Blauwkamp, J. M., \& Wesselink, P. (2001). Boxing Helena and corseting Eunice: Sexual rhetoric in Cosmopolitan and Playboy magazines. Sex Roles, 44, 751-771.

Kunkel, D., Biely, E., Eyal, K., Cope-Farrar, K., Donnerstein, E., \& Fandrich, R. (2003). Sex on TV 3: A biennial report of the Kaiser Family Foundation. Santa Barbara, CA: Kaiser Family Foundation

Lanis, K., \& Covell, K. (1995). Images of women in advertisements: Effects on attitudes related to sexual aggression. Sex Roles, 32, 639-649.

Levant, R. F. (1997). Nonrelational sexuality in men. In R. F. Levant \& G. R. Brooks (Eds.), Men and sex: New psychological perspectives (pp. 9-27). New York: Wiley.

MacKay, N. J., \& Covell, K. (1997). The impact of women in advertisements on attitudes toward women. Sex Roles, 36, 573-583.

Maxim Online. (2003). The Maxim reader. In Maxim Media Kit. Retrieved October 10, 2003, from http://www. maximonline.com.

Neuendorf, K. A. (2002). The content analysis guidebook. Thousand Oaks, CA: Sage.

Oliver, M. B., \& Hyde, J. S. (1993). Gender differences in sexuality: A meta-analysis. Psychological Bulletin, 114, 29-51.

Phillips, L. M. (2000). Flirting with danger: Young women's reflections on sexuality and domination. New York: New York University Press.

Reichert, T., Lambiase, J., Morgan, S., Carstaphen, M., \& Zavoina, S. (1999). Cheescake and beefcake: No matter how you slice it, sexual explicitness in advertising continues to increase. Journalism and Mass Communication Quarterly, 76, 7-20.

Schmitt, D. P., \& 118 members of the International Sexuality Description Project. (2003). Universal sex differences in the desire for sexual variety: Tests from 52 nations, 6 continents, and 13 islands. Journal of Personality and Social Psychology, 85, 85-104.

Spanier, G. B. (1977). Sources of sex information and premarital sexual behavior. Journal of Sex Research, 13, 73-88.

Treise, D., \& Gotthoffer, A. (2002). Stuff you couldn't ask your parents: Teens talking about using magazines for sex information. In J. D. Brown, J. R. Steele, \& K. Walsh-Childers (Eds.), Sexual teens, sexual media: Investigating media's influence on adolescent sexuality (pp. 173-189). Mahwah, NJ: Erlbaum. 